\title{
Aerobic exercise repairs neurological function after cerebral ischaemia by regulating the nitric oxide
}

\author{
LEI SUN $^{1}$, LV-PING ZHUANG ${ }^{2}$ and WEI-FENG WU ${ }^{1}$ \\ ${ }^{1}$ Sports Teaching and Research Department, Fujian Medical University, No. 1 Xuefu \\ North Road, University Town, Fuzhou, 350001 Fujian Province, China \\ ${ }^{2}$ Department of Neurology, Fujian Medical University Union Hospital, No. 29 \\ Xinquan Road, Fuzhou, 350001 Fujian Province, China \\ Manuscript received on January 1, 2019; accepted for publication on July 3, 2019
}

\begin{abstract}
How to cite: SUN L, ZHUANG L-P AND WU F-F. 2019. Aerobic exercise repairs neurological function after cerebral ischemia by regulating the nitric oxide. An Acad Bras Cienc 91: e20190068. DOI. 10.1590/00013765201920190068
\end{abstract}

\begin{abstract}
To investigate the mechanism of different exercise patterns on neurological function after focal cerebral ischaemia in rats. Rats with focal cerebral cerebral ischaemia were randomly divided into an aerobic exercise group, an exhaustive exercise group and a control group, with 8 rats in each group. A score for nerve function in each group was calculated, and the ultrastructure of nerve cells was observed. Levels of NO and NOS in the brain motor area of the rats were measured in each group. The aerobic exercise group had lower nerve function scores than the exhaustive exercise group and higher scores than the control group $(\mathrm{P}<0.05)$. Under transmission electron microscopy, irregular shapes and organs were observed in nerve cells in the control group, while regular cell shapes and organs were observed in the aerobic exercise group. The aerobic exercise group and exhaustive exercise group had higher measures of NO content, NOS activity and eNOS, nNOS and iNOS gene expression than the control group, but eNOS expression in the aerobic exercise group and iNOS expression in the exhaustive exercise group were clearly higher according to RT-PCR $(\mathrm{P}<0.05)$. Aerobic exercise can promote the expression of NOS, mainly in eNOS, which can promote nerve repair.
\end{abstract}

Key words: exercise intensity, cerebral ischaemia, nervous function, repair, NO, NOS.

\section{INTRODUCTION}

Clinically, cerebral ischaemia and hypoxia are the most common pathophysiological processes in central nervous system diseases, often leading to different degrees of pathological change and functional loss of nervous system structure, with high mortality and disability (Yamashita et al. 2016, Lindsay et al. 2015). These statistics

Correspondence to: Wei-Feng Wu

E-mail: ydwwf@126.com

ORCid: https://orcid.org/0000-0002-9505-3548 highlight the critical role cerebral ischaemia and hypoxia play in human life and quality of life. Studies have shown that approximately $50-85 \%$ of patients with cerebral ischaemia and hypoxia have varying degrees of hemiplegia, which imposes a heavy economic and mental burden on society and families (Coughlan and O'Neill 2004, Jenkinson et al. 2011, Laurent et al. 2011). Animal experiments and clinical studies have shown that the pathophysiological processes of ischaemia and hypoxia involve very complicated changes in brain tissue that occur simultaneously and ultimately 
lead to structural and functional disorders of the nervous system (Zhuoran 2019, Zhifeng 2019). At present, research on the pathogenesis of injury related to cerebral ischaemia and hypoxia mainly focuses on free radicals, excitatory amino acids, intracellular calcium overload and so on (Baklavadzhian et al. 1999, Rodrigo et al. 2005, Yang et al. 2016). The study of neurological recovery after cerebral ischaemia mainly focuses on neurotrophic factors (Kiprianova et al. 1999), replacement of necrotic nerve cells by stem cell transplantation (Zhang et al. 2010), or application of molecular biology techniques to inhibit damage to nerve cells due to local virulence factors (Chamorro et al. 2016). The use of exercise therapy to promote structural and functional recovery of the nervous system after ischaemia has rarely been reported in the literature. Aerobic exercise methods include moderate swimming, running, ball games and other outdoor sports (Squires 1995), which can effectively modulate various functions of the body and improve health. Experimental studies related to the repair of cerebral ischaemic nerve function by aerobic exercise are not only beneficial in standardizing the rational treatment of limb hemiplegia but also in promoting the effective recovery of nerve function. Such studies have the potential for broad applications and to further promote aerobic exercise. Popularizing national fitness campaigns has far-reaching significance. It has been reported in the literature that the loss of neurological function after cerebral infarction is related to the expression of nitric oxide (NO) and nitric oxide synthase (NOS) (Wei et al. 1999, Panahian et al. 1996). There are three types of NOS: endothelial nitric oxide synthase (eNOS), neuronal nitric oxide synthase (neuronal NOS, nNOS) and inducible nitric oxide synthase (inducible NOS, iNOS) (Takimoto et al. 2000). The dual role of NO is relatively brief in cerebral ischaemia. A classic animal model for studying the mechanism and treatment of cerebral ischaemic hemiplegia is the rat model of focal cerebral ischaemia. In this study, a rat model of focal cerebral ischaemia was established by occlusion of the rat's right middle cerebral artery occlusion (MCAO) (Menzies et al. 1992). The purpose of this study was to investigate the role of aerobic exercise in reducing neurological deficits and cerebral ischaemia and to examine the mechanisms of post-neural cell repair.

\section{MATERIALS AND METHODS}

\section{EXPERIMENTAL ANIMAL}

All animal work procedures were performed in accordance with the Animal Care Committee of Fujian Medical University, China (protocol number: FJMUIACUC3423). Twenty-four healthy

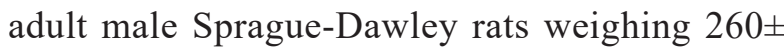
$10 \mathrm{~g}$, clean grade, from Zhejiang Experimental Animal Center were given free access to a standard diet and maintained in an indoor environment with temperature controlled at $20^{\circ} \mathrm{C} \sim 24{ }^{\circ} \mathrm{C}$.

\section{ESTABLISHMENT OF A RAT MODEL OF FOCAL CEREBRAL ISCHAEMIA}

Rats were housed in cages, and after 1 week of adaptation, abdominal anaesthesia (2\% sodium pentobarbital: $35 \mathrm{mg} / \mathrm{kg}$ ) was used. A rat model of cerebral ischaemia was established by occlusion of the right middle cerebral artery with thread embolism according to previous study (Longa et al. 1989). Rats were randomly divided into a control group, an exhaustive exercise group and an aerobic exercise group, with 8 rats in each group.

\section{EXERCISE PATTERNS}

Both the aerobic exercise group and the exhaustive exercise group used an incremental strength method for treadmill exercise. Exercise load was carried out according to previous study (Bedford et al. 1979). The aerobic training group carried out treadmill exercise 5 days per week, for 4 weeks at an initial speed of $15 \mathrm{~m} / \mathrm{min}$ and session length of $20 \mathrm{~min}$. Speed was increased incrementally by $3 \mathrm{~m} / \mathrm{min}$ and time by 5 min until movement speed was $20 \mathrm{~m} /$ min and time was $60 \mathrm{~min}$. The running platform 
slope was increased by $5 \%$. The exhaustive training group exercised 6 days per week for 4 weeks, with speed increasing by $3 \mathrm{~m} / \mathrm{min}$ and time by $5 \mathrm{~min}$ increments. The initial exercise speed was $35 \mathrm{~m} /$ min, and the running platform slope was increased by $10 \%$ after $60 \pm 10 \mathrm{~min}$. The control group was fed normally in the cage and did not exercise.

\section{NEUROLOGICAL DEFICIT SCORE}

Neurological deficit scores were collected for each rat at the indicated time points. The scores were based on Longa and Bederson's method. The scoring system was as follows: 0 points, no symptoms of nerve damage; 1 point, the contralateral forepaws could not be fully extended; 2 points, turn to the outside (left); 3 points, dump to the opposite side; 4 points, score cannot be assessed due to loss of consciousness.

\section{BRAIN TISSUE SPECIMENS}

Each modelled rat was deeply anaesthetized at a specified time point. The aorta was quickly flushed with normal saline, then the rat's head was cut to expose the brain tissue, which was quickly removed and embedded in ice. The right side of the brain, $2.5 \mathrm{~mm}$ from the frontal margin (the lateral dorsolateral cortex and basal ganglia), was weighed and divided into several equal parts of $0.1 \mathrm{~g}$ each. One of the parts was quickly placed in the electron microscope fixing solution, and the remaining parts were stored and kept for use in a $-70{ }^{\circ} \mathrm{C}$ refrigerator. All animal work procedures were performed in accordance with the Animal Care Committee of Fujian Medical University, China (protocol number: FJMUIACUC3423).

TRANSMISSION ELECTRON MICROSCOPY OBSERVATION

One sample from each group of brain tissue samples was randomly selected and fixed with $3 \%$ glutaraldehyde- $1.5 \%$ paraformaldehyde, and then $1 \%$ citric acid- $1.5 \%$ potassium ferrocyanide, after which an alcohol-acetone solution was used. Subsequent preparation of the sample included dehydration, embedding with epoxy resin 618 embedding agent, cutting into ultra-thin sections, staining with uranyl acetate and lead citrate, and finally using a Hitachi Hu-12A (Philips 208 type) transmission electron microscope to observe and photograph the section.

\section{MEASUREMENTS OF NO CONCENTRATION AND NOS ACTIVITY IN BRAIN TISSUE}

One specimen was randomly selected from each group of brain tissue. The blood on the specimen was washed with $4{ }^{\circ} \mathrm{C}$ pre-cooled physiological saline, $0.1 \mathrm{~g}$ homogenate was centrifuged for 10 $\min (4000 \mathrm{rpm} / \mathrm{min})$, and the separated supernatant was used separately. The determination of NOS activity and NO content was performed following the procedure on the kit instructions. NO nitrate reductase assay kit was purchased from Wuhan Boster Reagent Co., Ltd., and NOS activity assay kit was purchased from Nanjing Bioengineering Co., Ltd.

SEMI-QUANTITATIVE ANALYSIS OF eNOS, nNOS AND iNOS GENES IN BRAIN TISSUE BY RT-PCR

A random sample was taken from each group of brain tissue samples, RNA was extracted with TRIzol reagent, and total RNA concentration was calculated. Two $\mu \mathrm{g}$ of total RNA was measured for reverse transcription and used as a template. The RNA, $2 \mu \mathrm{L}$ of reverse transcription reaction solution, and primers ( $\beta$-actin, internal reference) were subjected to PCR amplification in a total reaction volume of $50 \mu \mathrm{L}$. The selected primers were eNOS (F 5'-AGAGCATACCCGCACTTCTG-3'; R 5'-GGAAGTAAGTGAGAGCCTGG-3'), nNOS (F 5'-ACAAAGGAATGAATCCGTGCC-3'; R 5'-GGCAGGAGGATCCAGTTAG-GA-3'), iNOS (F 5 '-CACGGAGAACAGCAGAGTTGG-3'; R 5'-TTGTGGTGAAGGGTGTCGTG-3'), $\beta$-actin (F 5'-CAGAGCAAGAGAGGCATCCT-3'; R 5'- GGATAGCACAGCCTAGATAG-3'). 
Amplification conditions were as follows: predenaturation at a high temperature of $94{ }^{\circ} \mathrm{C}$ for 5 min, then denaturation at $94{ }^{\circ} \mathrm{C}$ for $30 \mathrm{~s}$, followed by renaturation (eNOS: $58{ }^{\circ} \mathrm{C}$; nNOS: $55{ }^{\circ} \mathrm{C}$; iNOS: $55^{\circ} \mathrm{C}$ ) for $30 \mathrm{~s}$, then extension at $72{ }^{\circ} \mathrm{C}$ for 1 min (the above steps cycle 35 times), after which extension was continued for $7 \mathrm{~min}$ at $72{ }^{\circ} \mathrm{C}$. The PCR product was observed and photographed by $1.8 \%$ agarose gel electrophoresis and a BoleRAD Gel Doc ${ }^{\mathrm{TM}}$ XR gel imaging system, and the experiment was repeated 4 times independently. The $\beta$-actin internal reference was used as an internal standard and then synchronized with the product. For comparison, the quantitative PCR products were semi-quantitatively analysed using the Quantity One 1-D Analysis software. The mRNA level of a gene was determined by calculating the ratio of the integrated optical density of the obtained product to the respective internal reference integrated optical densities.

\section{STATISTICAL ANALYSIS}

All statistical analyses were performed using SPSS v. 20.0 for Windows (SPSS Inc., Chicago, IL, USA). The mean \pm standard deviation was calculated, and one-way ANOVA was performed. Values of $\mathrm{P}<0.05$ were considered statistically significant.

\section{RESULTS}

\section{NEUROLOGICAL DEFICIT SCORE}

The neurological deficit scores of the control group, aerobic exercise group and exhaustive exercise group were $1.64 \pm 0.25,0.75 \pm 0.15$ and $2.85 \pm 0.33$, respectively. The differences were statistically significant $(\mathrm{P}<0.05)$.

\section{OBSERVATION OF BRAIN TISSUE ULTRASTRUCTURE BY FLUOROSCOPY}

The cell morphology and nucleus were irregular in the control group (Figure 1). The cell morphology and nucleus in the aerobic exercise group were regular, with the cell surfaces rich in microvilli, and an increase in the number of organelles such as mitochondria, endoplasmic reticulum and lysosome (Figure 2). However, in the exhaustive exercise group, the nucleus was divided, with obvious mitochondrial swelling in the cytoplasm and even vacuolization changes (Figure 3).

\section{NO CONCENTRATION AND NOS ACTIVITY IN BRAIN TISSUE}

NO concentration and NOS activity were higher in the aerobic exercise group than in the control group but lower than in the exhaustive exercise group. The difference between the three groups was statistically significant $(\mathrm{P}<0.01)$ (Table I).

\section{SEMI-QUANTITATIVE ANALYSIS OF NOS GENE} RESULTS BY RT-PCR

The $\lambda$ value (OD260/OD280) of total RNA extracted from the brain tissue samples of each group was between 1.80 and 1.97. Gel electrophoresis showed that the RNA was not degraded. After electrophoresis of the RT-PCR product, the results showed that eNOS, iNOS, nNOS and the specific fragment sizes of $\beta$-actin were $625 \mathrm{bp}, 342 \mathrm{bp}$, $501 \mathrm{bp}$ and $250 \mathrm{bp}$, respectively. The ratios of the three NOS genes to the internal reference were different among the three groups $(\mathrm{P}<0.01)$, and the expression of the NOS gene increased with increasing exercise level (Table II).

\section{DISCUSSION}

Ischaemic brain injury is a serious disease with a high incidence, disability and mortality. It accounts for approximately $50-80 \%$ of all cerebrovascular diseases (Mozaffarian et al. 2016). The complications of ischaemic diseases have become a topic of considerable interest in sports medicine and rehabilitation medicine. At the same time, it is necessary to establish an ideal animal model of cerebral ischaemia with strict control of physiological indices, simple operation, stability, 

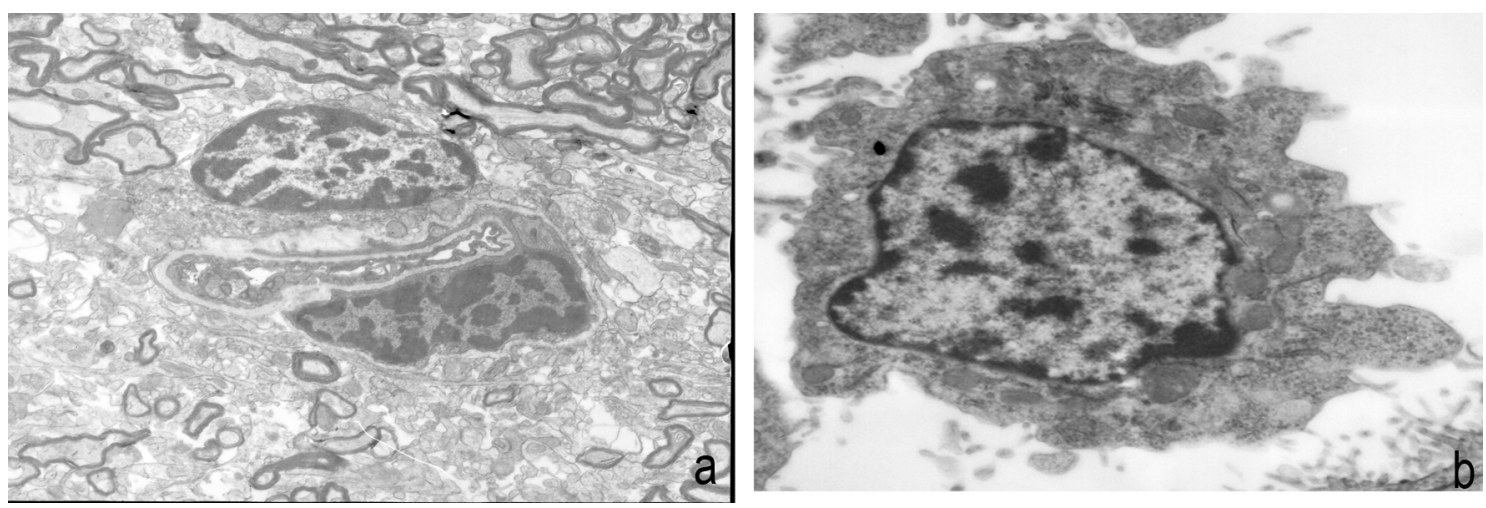

Figure 1 - Cell morphology and nucleus are irregular in the control group. a, multicells are shown in the micrographs; b, one cell is shown in the micrographs.
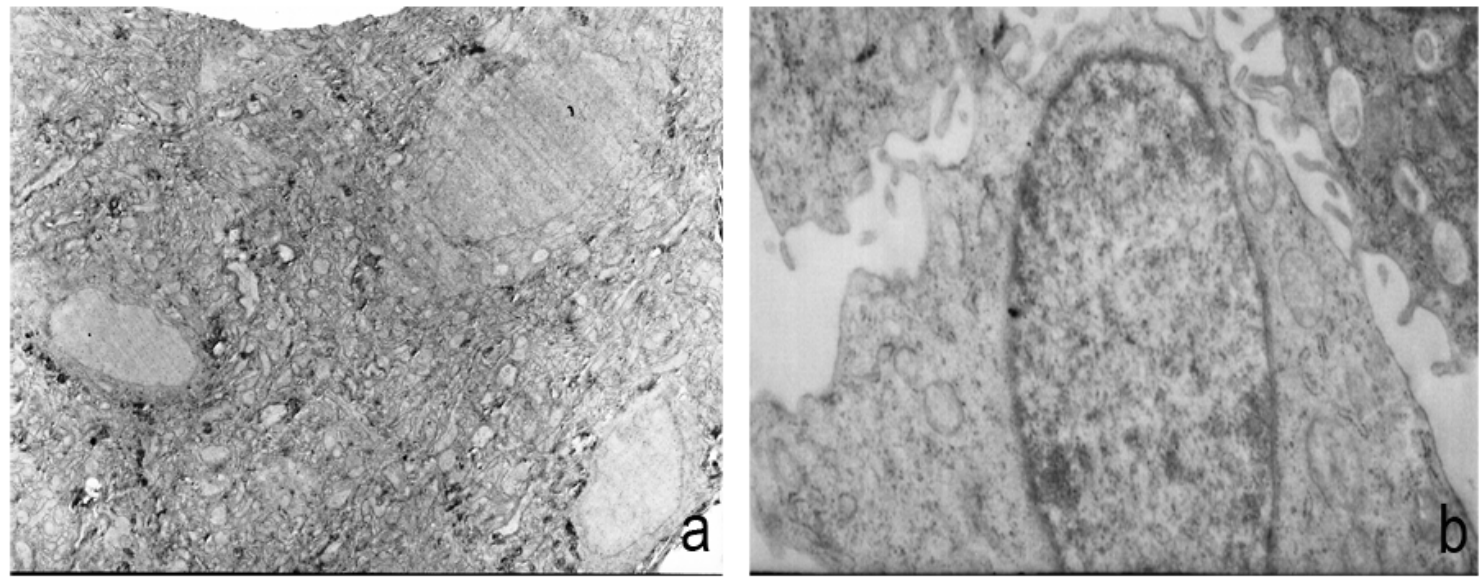

Figure 2 - Cell morphology and nucleus in the aerobic exercise group. a, multicells are shown in the micrographs; b, one cell is shown in the micrographs.
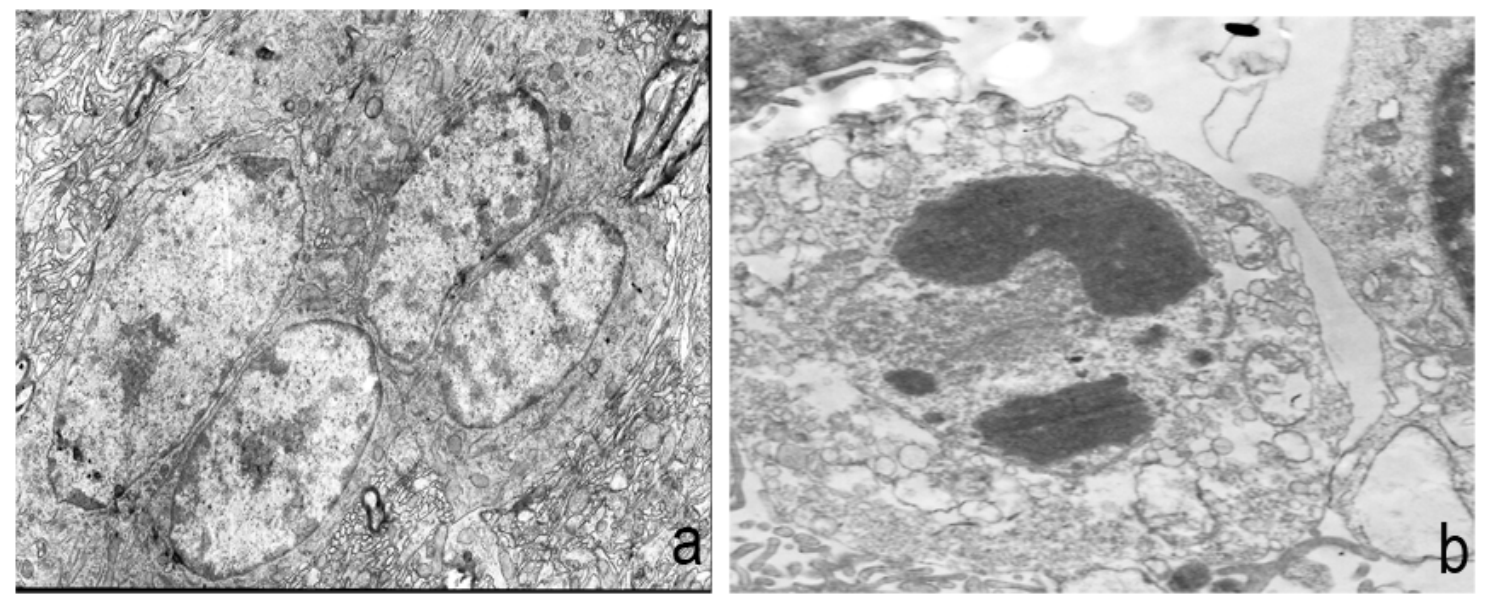

Figure 3 - Cell morphology and nucleus in the exhaustive exercise group. a, multicells are shown in the micrographs; b, one cell is shown in the micrographs. 
TABLE I

Changes in NO concentration and NOS activity in brain tissue of each group (Mean \pm standard deviation).

\begin{tabular}{cccc}
\hline Group & N & NO change $(\boldsymbol{\mu m o l} / \mathbf{g})$ & NOS activity $(\mathbf{n M} / \mathbf{m i n})$ \\
\hline Control & 8 & $0.27 \pm 0.01$ & $0.44 \pm 0.02$ \\
Aerobic exercise & 8 & $0.39 \pm 0.02^{* *}(\mathrm{t}=15.179)$ & $0.53 \pm 0.03^{\text {*** }}(\mathrm{t}=7.060)$ \\
Exhaustive exercise & 8 & $0.56 \pm 0.03^{\mathbf{\Lambda}}(\mathrm{t}=21.503)$ & $0.78 \pm 0.03^{\mathbf{\Delta}}(\mathrm{t}=16.667)$ \\
\hline
\end{tabular}

**: Compared the aerobic exercise group with the control group, $\mathrm{P}<0.01$;

$\Delta \mathbf{\Delta}$ : Compared the aerobic exercise group with the exhaustive exercise group, $\mathrm{P}<0.01$.

TABLE II

Changes in NOS gene expression in brain tissue of each group (Mean \pm standard deviation).

\begin{tabular}{|c|c|c|c|c|}
\hline Group & $\mathbf{N}$ & eNOS & nNOS & iNOS \\
\hline Control & 8 & $0.19 \pm 0.01$ & $0.21 \pm 0.01$ & $0.37 \pm 0.02$ \\
\hline Aerobic exercise & 8 & $0.43 \pm 0.02^{* *}(\mathrm{t}=10.119)$ & $0.32 \pm 0.03^{* * *}(\mathrm{t}=24.000)$ & $0.43 \pm 0.02^{* *}(\mathrm{t}=4.707)$ \\
\hline \multirow[t]{2}{*}{ Exhaustive exercise } & 8 & $0.29 \pm 0.02^{* * *}(\mathrm{t}=12.649)$ & $0.35 \pm 0.03^{* *}(\mathrm{t}=12.522)$ & \multirow[t]{2}{*}{$\begin{array}{c}0.68 \pm 0.05^{* *}(\mathrm{t}=16.282) \\
\mathbf{\Delta \Delta}(\mathrm{t}=13.131)\end{array}$} \\
\hline & & $\Delta \mathbf{\Delta}(\mathrm{t}=14.000)$ & $\Delta \mathbf{\Delta}(\mathrm{t}=2.000)$ & \\
\hline
\end{tabular}

**: Compared the aerobic exercise group with the control group, $\mathrm{P}<0.01$;

$\triangle \mathbf{\Delta}$ : Compared the aerobic exercise group with the exhaustive exercise group, $\mathrm{P}<0.01$.

reliability and reproducibility that is similar to the pathological process of human cerebral ischaemia. Establishing an animal model is essential for the study of the pathological mechanism and treatment of cerebral ischaemia. Ischaemic cerebrovascular disease is caused by middle cerebral artery occlusion (MCAO). Therefore, the study of a focal cerebral ischaemia model caused by middle cerebral artery occlusion is an important focus of research. Because the Longa line suture method replicates the characteristics of minor trauma, requires no craniotomy, has a high model success rate, and creates hemiplegia symptoms close to clinical presentation, it is the most widely used animal model of cerebral ischaemia (Longa et al. 1989). In this study, after a rat model of focal cerebral ischaemia was established by the Longa suture method, the rats had the following symptoms: hemiplegia mainly in the limbs contralateral to the side of operation and eyeball invagination on the side ipsilateral to the operation, in which the pupil was reduced and the ocular fissure became small. After treadmill exercise, the body of the rat rotated to the opposite side, and after stopping exercise, the tail had a specific coiled shape, and weight loss occurred. The appearance of these symptoms marked the successful establishment of a rat model of focal cerebral ischaemia, which is associated with the MCA (including the cervical sympathetic pathway and the advanced cortical control area of muscle strength and muscle tension). The above symptoms are present when the right middle artery is blocked. At the same time, treadmill exercise training is an important experimental research method for the rehabilitation of cerebral ischaemia rats. The advantages of rat treadmill exercise training methods are as follows: (1) The exercise mode is consistent with the daily exercise of rats; (2) The rats exercise independently in their respective channels, do not interfere with each other, and 
therefore have fewer potentially confounding interactions with each other; and (3) Compared with swimming, sports drums, jumping platforms, etc., treadmill movement can be more precise in terms of regulating exercise load, running slope and speed of rats. Therefore, this experimental study chose treadmill exercise training as the movement mode for the rats.

NO is an important messenger molecule and effector molecule in the body and is closely related to vascular smooth muscle relaxation, cardiovascular function and pathological and physiological processes of the nervous system (Heneka and Feinstein 2001, Stoyanova and Lazarov 2005). The neuroprotective effects of NO are mainly increased cerebral blood flow, anti-platelet and leukocyte aggregation adhesion, enhanced synaptic transmission, blocking of N-methyl-D-aspartate (NMDA) receptor, and inhibition of endothelin (ET) (Pekka et al. 1999, Watkins 1995). The generation of negative feedback regulation of neurons by NOS plays a protective role on the cranial nerve. Excessive excitatory amino acids (such as glutamate) that are produced during cerebral ischaemia over-stimulate NMDA receptors, increase the permeability of cell membranes to $\mathrm{Ca} 2+$, overload intracellular calcium ions, and then trigger a series of reactions, eventually leading to neuronal necrosis. At the same time, calcium overload also activates various enzymes such as phospholipase, protease and NOS, which causes NOS neurons to produce excessive NO. Excessive amounts of NO activate NMDA receptors and calcium channels, and extracellular calcium ions flood into cells, which further aggravate neuronal damage (Alagarsamy and Johnson 1995). In addition, under cerebral ischaemic conditions, excess NO can also exert neurotoxic effects through the formation of free radicals, damage mitochondria, etc. NOS is the rate-limiting enzyme for NO synthesis and is the most important link in the regulation of NO.
The expression of eNOS is mainly caused by the secretion of eNOS by vascular endothelial cells. The NO produced by dilating cerebral blood vessels increases cerebral blood flow and inhibits platelet and leukocyte aggregation adhesion. In the middle and late stages of cerebral ischaemia, nNOS and iNOS play a major role in mediating glutamate toxicity, generating oxygen free radicals, affecting cell mitochondrial function, increasing inflammatory response, inducing apoptosis, etc. The pathway produces neurotoxicity, and the expression of nNOS is not high. The iNOS produced by phagocytic cells and inflammatory cells in the infarct can mediate neuronal apoptosis through the relationship between NOS, caspase-3 and p38 MAPK, causing loss of neurological function (Plotkine and Margaill 2002).

Macko et al. 2006 confirmed that treadmill exercise can further improve the level of nerve regeneration in the hippocampus, whether it is the ischaemic side or the healthy side (Macko et al. 2006). The number of BrdU immunoreactive cells in the hippocampus and dentate gyrus of animals has been observed to be significantly higher than that in the control animals (Kim et al. 2014). A large number of experiments have confirmed that exercise training can promote the recovery of nerve function and body weight in ischaemic rats, reduce the volume of cerebral infarction in rats and is conducive to the rehabilitation of cerebral ischaemia in rats (Liu et al. 2011, Shamsaei et al. 2015). These experimental results are consistent with our previous findings. Aerobic training enhances neurological function after focal cerebral ischaemia in rats (Wu et al. 2008). In this group of experiments, the neurological deficit score in the aerobic exercise group was lower than that in the control group, and the rehabilitation of physical activity was good, indicating that aerobic exercise can improve hemiplegia after cerebral ischaemia. The expression levels of NO and NOS were related to different exercise intensities. ZJ 
Tian and other researchers also used the treadmill training method to establish a model of aerobic exercise and exhaustive exercise in rats (Zhenjun and Yuanli 2006). The expression of NOS in the renal cortex of rats increased with exercises of different intensity. NO production increased, but high-intensity exercise can promote apoptosis in the renal cortex of rats and is related to excessive production of NO. In the present experiment, NO and NOS levels increased to different degrees in the aerobic exercise group and the exhaustive exercise group compared with the control group. However, as observed by electron microscopy, the structural repair and neurological deficits of ischaemic nerve cells were significantly better in the aerobic group than in the exhaustive exercise group. The mechanism may be that aerobic exercise can promote the expression of eNOS, the main source of NOS, which in turn promotes the increase in NO synthesis and expands local blood vessels, improving the nutrition and promoting the structural and functional repair of ischaemic nerve cells. In contrast, the high-intensity exercise in the exhaustive exercise group caused the neurotoxicity of iNOS to be significantly increased and promoted the synthesis of NO, resulting in overexpression in local nerve cells.

Still, we have limitations in this study, due to ethical reason, just animal experiments have been undergone in our study, further clinical research is necessary. In conclusion, different exercise training intensities can promote the expression of $\mathrm{NO}$ and NOS in the cerebral ischaemic area. Aerobic exercise promotes the expression of eNOS, which plays a neuroprotective role, establishes collateral circulation, improves blood supply in local areas of cerebral infarction, and promotes nerve cells. Thus, structural repair and recovery of neurological function takes place. However, exhaustive exercise significantly increases the expression of iNOS, causing overexpression of NO, neurotoxicity to local nerve cells, and apoptosis. These findings are very important to the application of appropriate exercise intensity in the treatment of hemiplegia after cerebral ischaemia.

\section{AUTHOR CONTRIBUTIONS}

Lei Sun, Lv-Ping Zhuang and Wei-Fen Wu conceived of the study, analyzed the data, drafted the manuscript, read and approved the final manuscript.

\section{REFERENCES}

ALAGARSAMY S AND JOHNSON KM. 1995. Voltagedependent calcium channel involvement in NMDAinduced activation of NOS. Neuroreport 6: 2250-2254

BAKLAVADZHIAN MO,AKOPOVC SEAND DARBINIAN VZH. 1999. Cerebral ischemia and calcium overload. Zh Nevrol Psikhiatr Im S S Korsakova 99(11): 49-50.

BEDFORD TG, TIPTON CM, WILSON NC, OPPLIGER RA AND GISOLFI CV. 1979. Maximum oxygen consumption of rats and its changes with various experimental procedures. J Appl Physiol Respir Environ Exerc Physiol 47(6):1278-1283.

CHAMORRO Á, DIRNAGL U, URRA X AND PLANAS AM. 2016. Neuroprotection in acute stroke: targeting excitotoxicity, oxidative and nitrosative stress, and inflammation. Lancet Neurol 15: 869-881.

COUGHLAN T AND O'NEILL D. 2004. Hemiplegia of the will and trends in stroke incidence. Irish Med J 97: 294.

HENEKA MT AND FEINSTEIN DL. 2001. Expression and function of inducible nitric oxide synthase in neurons. J Neuroimmunol 114: 8-18.

JENKINSON PM, PRESTON C AND ELLIS SJ. 2011. Unawareness after stroke: a review and practical guide to understanding, assessing, and managing anosognosia for hemiplegia. J Clin Exp Neuropsyc 33: 1079-1093.

KIM BK, SHIN MS, KIM CJ, BAEK SB, KO YC AND KIM YP. 2014. Treadmill exercise improves short-term memory by enhancing neurogenesis in amyloid beta-induced Alzheimer disease rats. J Exerc Rehabil 10: 2-8.

KIPRIANOVA I, SANDK HLER J, SCHWAB S, HOYER S AND SPRANGER M. 1999. Brain-Derived Neurotrophic Factor Improves Long-Term Potentiation and Cognitive Functions after Transient Forebrain Ischemia in the Rat. Exp Neurol 159: 511-519.

LAURENT K, DESEZE MP, DELLECI C, KOLECK M, DEHAIL P, ORGOGOZO JM AND MAZAUX JM. 2011. Assessment of quality of life in stroke patients with hemiplegia. Ann Phys Rehabil Med 54: 376-390. 
LINDSAY P, FURIE KL, DAVIS SM, DONNAN GA AND NORRVING B. 2015. World stroke organization global stroke services guidelines and action plan. Int J Stroke 9: 4-13.

LIU N, HUANG H, LIN F, CHEN A, ZHANG Y, CHEN R AND DU H. 2011. Effects of treadmill exercise on the expression of netrin-1 and its receptors in rat brain after cerebral ischemia. Neuroscience 194: 349-358.

LONGA EZ, WEINSTEIN PR, CARLSON S AND CUMMINS R. 1989. Reversible middle cerebral artery occlusion without craniectomy in rats. Stroke 20: 84.

MACKO RF, IVEY FM, FORRESTER LW, DANIEL H, SORKIN JD, KATZEL LI, SILVER KH AND GOLDBERG AP. 2005. Treadmill exercise rehabilitation improves ambulatory function and cardiovascular fitness in patients with chronic stroke: a randomized, controlled trial. Stroke 36: 2206-2211.

MENZIES SA, HOFF JT AND BETZ AL. 1992. Middle cerebral artery occlusion in rats: a neurological and pathological evaluation of a reproducible model. Neurosurgery 31: 106-107.

MOZAFFARIAN D, BENJAMIN EJ AND GO AS. 2016. Executive Summary: Heart Disease and Stroke Statistics-2016 Update: A Report From the American Heart Association. Circulation 127: 143-152.

PANAHIAN N, YOSHIDA T, HUANG PL, HEDLEYWHYTE ET, DALKARA T, FISHMAN MC AND MOSKOWITZ MA. 1996. Attenuated hippocampal damage after global cerebral ischemia in mice mutant in neuronal nitric oxide synthase. Neuroscience 72: 343.

PEKKA R, TSUGUNOBU A AND CHIUEH CC. 1999. Neuroprotective properties of nitric oxide and S-nitrosoglutathione. Ann NY Acad of Sci 890: 301.

PLOTKINE M AND MARGAILL I. 2002. NO synthases: new pharmacological targets in cerebrovascular accident? Thérapie 57: 548.

RODRIGO J, FERNNDEZ AP, SERRANO J, PEINADO MA AND MART NEZ A. 2005. The role of free radicals in cerebral hypoxia and ischemia. Free Radical Bio Med 39: 26-50.

SHAMSAEI N, KHAKSARI M, ERFANI S, RAJABI H AND ABOUTALEB N. 2015. Exercise preconditioning exhibits neuroprotective effects on hippocampal CA1 neuronal damage after cerebral ischemia. Neural Regen Res 10: 1245-1250.
SQUIRES RW. 1995. Essentials of Exercise Physiology. Mayo Clin Proc 70: 104.

STOYANOVA II AND LAZAROV NE. 2005. Localization of nitric oxide synthase in rat trigeminal primary afferent neurons using NADPH-diaphorase histochemistry. J Mol Histol 36: 187-193.

TAKIMOTO Y, AOYAMA T, KEYAMURA R, SHINODA E, HATTORI R, YUI Y AND SASAYAMA S. 2000. Differential expression of three types of nitric oxide synthase in both infarcted and non-infarcted left ventricles after myocardial infarction in the rat. Int J Cardiol 76: 135145.

WATKINS LD. 1995. Nitric oxide and cerebral blood flow: an update. Cerebrovas Brain Met 7: 324.

WEI G, DAWSON VL AND ZWEIER JL. 1999. Role of neuronal and endothelial nitric oxide synthase in nitric oxide generation in the brain following cerebral ischemia. Biochim Biophys Acta 1455: 23-34.

WU W, CHEN C AND DONG H. 2008. An experimental study on the repair of nerve function after focal cerebral ischemia in rats by aerobic training (in Chinese). J Sports Sci 28(2): 59-63.

YAMASHITA T AND ABE K. 2016. Recent Progress in Therapeutic Strategies for Ischemic Stroke. Cell Transplant 25(5): 893-8898.

YANG R, CHEN K, ZHAO Y, TIAN P, DUAN F, SUN W, LIU Y, YAN Z AND LI S. 2016. Analysis of Potential Amino Acid Biomarkers in Brain Tissue and the Effect of Galangin on Cerebral Ischemia. Molecules (Basel, Switzerland) 21: 438.

ZHANG P, LI J, LIU Y, CHEN X, KANG Q, ZHAO J AND LI W. 2010. Human neural stem cell transplantation attenuates apoptosis and improves neurological functions after cerebral ischemia in rats. Acta Anaesth Scand 53: 1184-1191.

ZHENJUN T AND YUANLI M. 2006. Effects of different intensity exercise on the expression of NOS and Bcl-2/Bax in rat kidney cortex. J Shaanxi Norm Univ 34(2): 105-109.

ZHIFENG Q AND KE JIAN L. 2019. The interaction of zinc and the blood-brain barrier under physiological and ischemic conditions. Toxicol Appl Pharmacol 364: 114119.

ZHUORAN W AND YANG W. 2019. Impaired capacity to restore proteostasis in the aged brain after ischemia: Implications for translational brain ischemia research. [J]. Neurochem Int 127: 87-93. 